\title{
Los Retos de la Educación Intercultural en el Siglo XXI
}

\section{The Challenges of Intercultural Education in the 21st Century}

\author{
Francisco Guzmán Marín * \\ Universidad Pedagógica Nacional, México
}

\begin{abstract}
En esencia, la educación moderna tiene un carácter de evangelización sociocivilizatoria en los valores, tradiciones y formas de pensamiento occidental, consiguiendo de esta forma "crear una nueva especie: los asiáticos helenizados, los negros grecolatinos y los indígenas occidentalizados”, siguiendo el lance de reflexión de Jean-Paul Sartre (2008); sin embargo, dados los profundos cambios socioculturales que han transformado las sociedades contemporáneas, en el orden global, el paradigma socio-educativo que mejor responde a las exigencias, demandas y retos histórico-civilizatorios propuestos por la dinámica propia de los nuevos contextos de construcción de la sociedad plural y multicultural, al propio tiempo que constituye una estrategia transversal a los procesos formativos institucionales, es el modelo de la Educación Intercultural, en cuanto dispositivo emergente de la formación societal desde, en y para la diversidad socio-cultural.
\end{abstract}

Descriptores: Educación multicultural; Multiculturalismo; Pluriculturalismo; Educación intercultural; Tiempos modernos.

\begin{abstract}
In essence, modern education has a character of socio-civilizational evangelization in Western values, traditions and ways of thinking, thus achieving "to create a new species: the Hellenized Asians, the Greco-Latin blacks and the Westernized Indians", following the Reflection by Jean-Paul Sartre (2008); however, given the profound socio-cultural changes that have transformed contemporary societies, in the global order, the socio-educational paradigm that best responds to the demands, demands, and historical-civilizing challenges proposed by the dynamics of the new contexts of The construction of the plural and multicultural society, at the same time that it constitutes a transversal strategy to the institutional formative processes, is the model of the Intercultural Education, as an emergent device of the societal formation from, in and for the socio-cultural diversity.
\end{abstract}

Keywords: Multicultural education; Multiculturalism; Pluriculturalism; Intercultural education; Modern times.

\begin{abstract}
Los sistemas educativos deben asegurar unas bases sólidas para la igualdad de oportunidades en la escuela, el trabajo y la sociedad, atendiendo a la diversidad de géneros, etnias y culturas a partir de un reconocimiento entre iguales basado en el respeto a la diversidad. Juan (José Leiva Olivencia)
\end{abstract}

\section{Introducción}

La Educación Moderna se encuentra determinada por cinco principios fundamentales del pensamiento enciclopédico-ilustrado, a saber: en primer lugar, la igualdad ontológica, inherente e irrevocable, del ser humano, como ya se previene en la Declaración de los Derechos del Hombre y del Ciudadano de 1789, y cuyo sentido histórico-filosófico se ha venido reiterando en las diversas generaciones de las declaratorias universales de los

*Contacto: coraxthelastone@hotmail.com

ISSN: 0718-7378

www.rinace.net/rlei/
Recibido: 24/11/2017

$1^{\text {a }}$ Evaluación: 23/02/2018

Aceptado: 27/02/2018 
Derechos Humanos; en segundo lugar, el progreso socio-cultural como factor fundamental del desarrollo socio-civilizatorio de las comunidades humanas; en tercer lugar, el emplazamiento del conocimiento formal (científico-disciplinario y técnicotecnológico), en cuanto agente privilegiado, exclusivo, legítimo y decisivo de la reforma moral de los individuos y de las sociedades, al propio tiempo que causa primordial de las transformaciones societales; en cuarto lugar, la institucionalización de la formación social de las personas, comunidades y sociedades nacionales, conforme a los objetivos del proyecto político-económico-cultural que sustentan los diversos aparatos del EstadoNación; y en quinto lugar, la proyección formativa del ciudadano para conformar la utópica sociedad del mañana, mediante reforma ontológica del ser humano que posibilite trascender las insuficiencias históricas del presente.

Allende las originales intenciones socio-históricas del pensamiento enciclopédicoilustrado, lo cierto es que, en la realidad de los Sistemas Educativos contemporáneos, estos mismos principios se han utilizado, de manera transversal y rizomática, tanto por los grupos político-económicos dominantes, como por los agentes en resistencia contrasistémica, para justificar, legitimar y promover prácticas socio-educativas homogéneas y homogenizantes, cuya función principal es el disciplinamiento social, mediante el cual se tiende a reproducir las formas de dominación económico-culturales vigentes, en donde más que formar a los individuos y comunidades se les informa parcialmente -y, en la mayoría de las ocasiones, de manera desfasada- sobre los productos del conocimiento formal, dentro de un ámbito de presunta profilaxis laica y desarraigado, por completo, de los intereses particulares de los individuos, familias y comunidades, así como de los constructos socio-identitarios del estrato histórico-cultural en que significan y desarrollan su vida cotidiana. En esencia, la educación moderna tiene un carácter de evangelización socio-civilizatoria en los valores, tradiciones y formas de pensamiento occidental, consiguiendo de esta forma "crear una nueva especie: los asiáticos helenizados, los negros grecolatinos y los indígenas occidentalizados", siguiendo el lance de reflexión de JeanPaul Sartre (2008). En efecto, la propia Educación Indígena, en América Latina, de manera histórica, se ha determinado por su función socio-civilizante, donde las lenguas nativas representan simples instrumentos estratégicos para hacer más eficiente los procesos educativos de evangelización cultural, o de "colonización del pensamiento", si se prefiere.

Si el pensamiento formal, a través de las prácticas científico-disciplinarias y técnicotecnológicas, ha constituido el dispositivo más eficiente de dominación y planetarización de la cultura occidental, por su parte, la educación moderna representa el dispositivo institucional, e institucionalizante, más eficaz de evangelización cultural y de disciplinamiento societal, mediante el cual se reproduce, arraiga y promueve tal sistema de dominio global de las sociedades humanas, desde aproximadamente el siglo XVI hasta la época contemporánea. Si se enajena la capacidad de decisión sobre la transmisión institucional de los valores, las tradiciones y las formas culturales de pensamiento, entonces, se instaura un sistema de dominio socio-político sobre los individuos, las comunidades y los pueblos, que opera a través del control de los sentidos y significados de la construcción identitaria, es decir, del control cultural, como bien parece advertir Guillermo Bonfil Batalla (1991). Y esta función reproductora del sistema de dominio socio-civilizatorio es la que realiza precisamente la educación moderna; las políticas educativas, la acción pedagógica y la certificación institucional imponen un paradigma ontológico y un modelo de significación socio-cultural que se presenta como el único modo legítimo de ser y de devenir en la historia, según lo han mostrado con bastante claridad 
ya Pierre Bourdieu y Jean-Claude Passeron (2005), aspecto en que parece coincidir la corriente pedagógica denominada como Pedagogía Crítica, encabezada por Peter Mclaren, Henry Giroux y Stephen Kemmis.

Sin embargo, si la escuela, en tanto espacio institucional, e institucionalizante, de las prácticas educativas modernas, es el ámbito propio de la reproducción político-económica de las sociedades occidentales, u occidentalizadas, por consecuencia, es también el territorio de la resistencia, de la lucha contra-cultural y/o de la deserción emergente de las disposiciones socio-civilizatorias instituidas. Parafraseando a Peter Mclaren (2005), bien es posible afirmar que "las escuelas están envueltas en la disputa por el 'espacio' cultural o aberturas en la cultura oficial dominante, ya que ésta nunca es capaz de asegurar el control total sobre los grupos culturales subordinados". Así, pues, en cuanto efecto de resonancia de las diversas confrontaciones civilizatorias que acontecen en la dimensión socio-política y económica-cultural, en la escuela moderna subyacen múltiples luchas de resistencia, contra-sistémicas y/o de evasión de los contenidos, significados y valores socio-civilizantes que comportan las prácticas educativas instituidas, esto tanto como producto de las crisis de significación que se presentan, de modo recurrente, en el orden social dominante y como consecuencia directa, también, de la diversidad socio-cultural que caracteriza la conformación de las sociedades contemporáneas, el movimiento punk y las tribus urbanas, o los pueblos indígenas y las poblaciones de migrantes, de manera respectiva, por ejemplo.

Los largos siglos de combate encarnizado de la civilización occidental a la diferencia, a la otredad -representada en las figuras del bárbaro, el salvaje, el aborigen, el indígena, etc., mediante la imposición cultural del Imperio del Significante de la identidad y la aplicación sistemática de las distintas estrategias de evangelización socio-civilizatoria, no consiguieron anular, ni mucho menos abolir, la diferencia onto-histórica de la existencia humana; más aún, las expresiones de la alteridad del ser humano se han diversificado, multiplicado y acentuado al interior mismo del proyecto socio-histórico de la civilización occidental, adquiriendo nuevas formas de representación y de significación cultural, tales como la diversidad de género, de capacidades, religión, clase económica y tradición etnográfica, entre otras. La institución escolar, en cuanto correlato de la diversa composición etnográfico-cultural de la sociedad moderna, no puede sustraerse a las luchas identitarias que devienen de esta inexorable eclosión de la diversidad onto-histórica. En el desarrollo de las prácticas socio-educativas se confrontan las distintas formas de significación que constituyen la identidad político-cultural de los diferentes agentes implicados en este proceso, tales como: instituciones internacionales (UNESCO), instancias nacionales (SEP), organismos locales (escuelas), políticos, pedagogos, psicólogos, sociólogos, trabajadores sociales, profesores, alumnos y padres de familia, por mencionar sólo algunos de lo que conforman las comunidades educativas modernas. De hecho, el fenómeno moderno de la educación se realiza en el diálogo, negociación, confrontación y/o resistencia de los valores socio-culturales que cada uno de estos agentes representa y suscribe.

La sociedad moderna se ha transformado de manera significativa en el último medio siglo, a consecuencia de la reorientación histórico-cultural de los fundamentos socio-filosóficos y de las prácticas político-económicas que originaron su articulación en cuanto proyecto de civilización planetaria. Los principales cambios socio-históricos que propician la postmoderna constitución de la transitiva sociedad contemporánea, los cuales impactan en la transitoria reforma del fenómeno educativo, son: el descrédito de los grandes meta- 
relatos que organizan la metafísica comprensión del desarrollo histórico de la civilización, preconizada de manera tan estridente por los pensadores postmodernos (Jean-Francois Lyotard, 2006, verbigracia); la Tercera Revolución Tecnológica que establece las condiciones de posibilidad para el surgimiento y arraigo de la Empresa Postindustrial, la Sociedad del Conocimiento y la Aldea Global, entre otros fenómenos; la emergente consolidación del Sistema Mundo, para decirlo en términos de Immanuel Wallerstein (2006) -mejor conocido como el fenómeno de la Globalización-, lo cual impacta en la erosión de las fronteras nacionales, el fortalecimiento de la influencia de los organismos multilaterales en el conjunto de las políticas locales -la ONU y la OCDE, por ejemplo-, la incentivación de los flujos de migración del Hemisferio Sur hacia el Hemisferio Norte, etc.; y el desarrollo de la cultura democrática que posibilita la reivindicación de las comunidades y de las culturas subalternas, así como el consecuente reconocimiento institucional de la Sociedad Plural y Multicultural.

El conjunto de estos fenómenos socio-históricos propicia el surgimiento de una múltiple serie de acontecimientos que impactan directamente en la re-significación y, por ende, en la sensible transformación de las prácticas socio-educativas modernas, entre las que se encuentran: el desplazamiento de la escuela como núcleo exclusivo y predominante de la formación societal; la constitución de espacios emergentes de difusión y promoción de los valores culturales de las comunidades subalternas, o subordinadas -las emisoras de radio y televisión indígenas, o comunales, verbigracia-; la diversificación de las modalidades y de las ofertas educativas que nomadizan, desterritorializan y des-institucionalizan las prácticas de la educación formal (la educación virtual, la educación a distancia, la educación abierta, los Massive Open Online Course [MOOC], por ejemplo); la flexibilización, o apertura, de los diseños, planes y programas nacionales de estudio; el fomento de la integración educativa, o Mainstreaming como le denomina J. W. Birch (1974), en cuanto estrategia democrática de incorporación de todos los sectores sociales a los proyectos de desarrollo nacional; y el impulso a los modelos pedagógicos de formación diferenciada, en función de los niveles particulares de desarrollo onto-genético, los intereses específicos de vida y los valores identitarios de los individuos y de las comunidades de que proceden, por mencionar sólo algunos de los más relevantes.

En este marco de significativas transformaciones socio-culturales del proyecto moderno de civilización, un fenómeno resulta por demás trascendente tanto para la constitución jurídico-política de las distintas disposiciones del Estado-nación, como para la definición de las políticas públicas de formación y disciplinamiento societal, esto es, el reconocimiento legal e institucional de la sociedad plural y multicultural-cuyos principios nodales se sintetizan en la Declaración Universal sobre la Diversidad Cultural, de la UNESCO del 2001-. Este hecho comporta dos implicaciones sustantivas para la proyección y concreción de las prácticas socio-educativas contemporáneas, a saber: por un lado, la aceptación tácita de que a los individuos y comunidades les asiste el derecho de apropiarse de los valores identitarios que constituyen a su propia cultura, en cuanto imperativo ético y derecho esencial de la dignidad humana, como se bien se puede advertir en la Declaración de la UNESCO sobre la Diversidad Cultural y en la Declaración de Friburgo sobre los Derechos Culturales, del 2007; y por otro lado, el principio fundamental de que los procesos educativos formales, además de generar competencias para la definición de su proyecto particular de vida y para participar activamente en el devenir histórico de su tradición cultural, a su vez, debe propiciar el desarrollo de competencias para convivir con la alteridad humana, es decir, para relacionarse con quienes disponen de cosmovisiones, 
lenguajes y prácticas identitarias distintas, según es posible colegir del informe que Jacques Delors (1996) presenta a la UNESCO. En esta perspectiva, el paradigma socioeducativo que mejor responde a las exigencias, demandas y retos histórico-civilizatorios propuestos por la dinámica propia de los nuevos contextos de construcción de la sociedad plural y multicultural, al propio tiempo que constituye una estrategia transversal a los procesos formativos institucionales, es el modelo de la Educación Intercultural, en cuanto dispositivo emergente de la formación societal desde, en y para la diversidad sociocultural.

\section{La educación intercultural}

En términos generales, la Educación Intercultural encuentra tres principales fuentes de fundamentación socio-histórica y, por ende, de definición conceptual, tales son: por una parte, "el resurgimiento y la redefinición de las identidades étnicas indígenas, en el contexto del así denominado "postindigenismo" latinoamericano", de acuerdo con Gunther Dietz y Laura Selene Mateos (2011, p. 21); por otra parte, la constitución de amplios pliegues multiculturales en las sociedades de economía desarrollada, en Europa y Estados Unidos, principalmente, como producto de los flujos migratorios del Hemisferio Sur al Hemisferio Norte -de África y Medio Oriente a Europa, de Latinoamérica a Estados Unidos y de China al resto del mundo-; y por último, aunque no siempre considerado por los especialistas en la materia, las luchas por la autonomía política de las diferentes regiones socio-culturales de la Comunidad Europea -el país Vasco en España, los Húngaros en Rumania e Irlanda del Norte en Gran Bretaña; esto sin soslayar, la lucha por la autonomía de más 30 millones de kurdos que se hallan repartidos en cuatro países del Oriente Medio: Turquía, Irán, Irak y Siria, por ejemplo-, luchas que tienen como sustento nodal de su reclamo jurídico-legal, la defensa de su lengua, tradición cultural y valores identitarios. Como los grandes meta-relatos de la filosofía socio-civilizatoria occidental, el sueño de la igualdad onto-histórica y de la homogeneidad cultural del Estado-Nación que nutrió el proyecto de la Modernidad, se derrumba ante la incontenible eclosión de la diversidad étnico-cultural que subyace, subalterna y underground, resistiendo a los embates del disciplinamiento societal de la cultura oficial, emplazada en cuanto institución legítima y legitimante.

Un conjunto de acontecimiento que parece marginal para quienes se encuentran inmersos en el proceso de construcción del concepto de la educación intercultural y/o en su concreción práctica en los Sistemas Educativos contemporáneos, pero que, sin embargo, constituye un amplio frente de lucha por el reconocimiento jurídico-político de la pluralidad y la multiculturalidad en el seno mismo de las naciones que suelen definirse como "monoculturales" y, al mismo tiempo, en los dispositivos de la planetarización homogenizante de los valores occidentales -y que de hecho, han contribuido de manera significativa en el logro histórico de tal reconocimiento-, es la confluencia de los movimientos contra-culturales emergentes con las corrientes de defensa de la diversidad de género, de capacidades diferentes y de libertad religiosa, entre muchos otros. Las comunidades que suscriben estos movimientos sociales, en la mayoría de las ocasiones comparten la misma situación marginada, subalterna y underground ante la cultura oficial dominante, que los grupos étnicos indígenas, los migrantes y los pueblos que defienden su autonomía legal. La diversidad no se explica solamente por las distinciones del lenguaje, las tradiciones histórico-culturales o los valores de construcción identitaria, sino que 
también proviene de las distintas formas de ser, de situarse en mundo y de perfilar su proyecto particular de vida. Las sociedades monoculturales no son más que un crisol de múltiples modos de agenciarse y de devenir las prácticas socio-culturales vigentes, que los dispositivos de represión y de disciplinamiento societal del Imperio del Significante de la Identidad no han conseguido depurar; el ideal moderno de la igualdad identitaria se esfuma ante la pluralidad onto-histórica del acontecer humano.

En el fondo, lo que articula estos diferentes fenómenos sociales que originan la necesidad histórica de la educación intercultural es la defensa del derecho a la diferencia y de que ésta no puede ser factor de exclusión, marginación y/o discriminación socio-política y/o económico-cultural. En este sentido, Maider Maraña, Responsable Cultura para el Desarrollo de la UNESCO Etxea, en relación con la Observación General $\mathrm{N}^{\circ} 21$ Derecho de toda Persona a Participar en la Vida Cultural, del Pacto Internacional de Derechos Económicos, Sociales y Culturales, recupera que:

En particular, nadie puede ser discriminado por el hecho de querer optar por
pertenecer o no a una comunidad o grupo cultural determinado, o por el hecho de
ejercer o no una actividad cultural. Igualmente, nadie quedará excluido del acceso a
las prácticas, los bienes y los servicios culturales. (Maraña, 2010, p. 14)

Los remanentes del sentido histórico que comportan estos distintos fenómenos socioculturales todavía pueden advertirse, con toda claridad, en los diversos esfuerzos de conceptuación y de construcción de propuestas operativas prácticas de la educación intercultural, que realizan las diferentes disciplinas del conocimiento contemporáneo, entre las cuales se encuentran: la filosofía, la historia, el derecho, la psicología, genética, sociología, antropología, lingüística y pedagogía, por mencionar sólo algunas de las más importantes en este campo. De ahí, pues, que desde la vertiente de comprensión latinoamericana, y con mayor especificidad en México, prevalezca lo que podría denominarse, de alguna manera, como la concepción "indigenizada" de la interculturalidad, por lo menos en tres posibles tendencias, esto es: primera, como redefinición emergente de la educación indígena, bajo el propósito de trascender el carácter socio-civilizante y colonizador que tradicionalmente le han impuesto los diferentes gobiernos del área, aún bajo la modalidad del bilingüismo -según resulta patente con la instauración de la Universidad Intercultural Indígena de Michoacán y la Universidad Intercultural Maya de Quintana Roo, por ejemplo-; segunda, en tanto estrategia educativa transversal de mediación entre las culturas nativas y el criollismo predominante en la cultura mestiza del continente; y tercera, en cuanto ideología de las políticas educativas diferenciadas para grupos autóctonos minoritarios, siguiendo los planteamientos de Dietz (2003), la cual sirve tanto para fundamentar el derecho de los pueblos indígenas de preservar los contenidos socio-identitarios de su propia cultura -el lenguaje, las tradiciones históricas, los usos y costumbres, etc.-, como para sustentar mecanismos de "discriminación positiva”, por parte de los gobiernos locales -según sucede con el Programa de las 900 Escuelas en Chile, el Programa Acciones Compensatorias para Abatir el Rezago Educativo en Educación Inicial y Básica en México, el Programa Nacional de Escuelas Prioritarias en Argentina y el Fundoescola en Brasil.

Ahora bien, de acuerdo con Dietz y Mateos (2011), en el territorio anglosajón, con la intención de que determinadas minorías étnicas, autóctonas y alóctonas, se empoderen de sus procesos de identidad, etnogénesis y "emancipación", se reconoce la necesidad de introducir el multiculturalismo en el Sistema Educativo, a través de "acciones afirmativas" o "discriminación positiva", tales como becas, procesos de selección, subsidios y 
exoneración de impuestos preferenciales para estos sectores. Mientras que en el espacio continental europeo, siguiendo el lance de análisis de estos mismos autores, más que en las necesidades de empoderamiento político-cultural de las minorías, tal cual sucede en el Reino Unido, los Estados Unidos y Canadá, el énfasis de la educación intercultural se concentra en la exigencia histórica de impulsar el desarrollo de competencias de coexistencia y convivencia social, que respondan con eficacia a los nuevos retos que plantea el complejo ambiente de sociedades diversificadas, plurales y multiculturales. La diferencia política radica en que el impulso al multiculturalismo educativo, de cuño anglosajón, se centra en las acciones compensatorias sobre los sectores de población tradicionalmente excluidos, discriminados y/o subordinados por diferencias raciales, económicas, étnicas o culturales; en tanto que la educación intercultural, de la Europa continental, se percibe como una estrategia de formación transversal que pretende el desarrollo de competencias interculturales de interacción social, tanto en las sociedades mayoritarias marginadoras como en los grupos minoritarios marginados. Gunther Dietz y Laura Selene Mateos lo sintetizan de la siguiente manera

En este sentido, mientras que en Estados Unidos y el Reino Unido se tiende a una educación empoderadora enfocada hacia las minorías, en la Europa continental se está optando por una educación que transversaliza el fomento de las competencias interculturales tanto de las minorías marginadas como sobre todo de las mayorías marginadoras. (Dietz y Mateos, 2011, p. 18)

Estas dos estrategias emergentes de comprensión socio-educativa: el multiculturalismo educativo y la educación intercultural, comparten dos aspectos de definición políticoconceptual, a saber: por un lado, el reconocimiento de la coexistencia de dos o más estratos culturales en un mismo espacio político-geográfico; y por otro lado, la persistencia histórica de una relación de poder entre los grupos mayoritarios dominantes que buscan la imposición de sus valores identitarios mediante la homogenización de la formación societal y los colectivos minoritarios subalternos que resisten tales empeños de evangelización socio-civilizatoria, al propio tiempo que reivindican sus propias tradiciones histórico-culturales. "La educación intercultural parte del hecho sociológico de la existencia de diferentes grupos culturales, uno mayoritario y otros en minoría", señala Rafael Sáez (2006, p. 870) En consecuencia, la definición de la interculturalidad se deriva de la explicación socio-antropológica del fenómeno del multiculturalismo, sus causas, formas de acontecimientación y consecuencias político-culturales y económico-sociales, como se puede apreciar en el lance de análisis seguido por Dietz y Mateos (2011), Sáez (2006), Abdallah-Pretceille (2001) y Aneas (2005), entre muchos otros; en función de lo cual se proponen tres principales factores de construcción de las propuestas interculturales de educación, tales son: primero, la afirmación reivindicativa de los valores culturales de constitución identitaria de los pueblos marginados; segundo, el multilingüismo como medio de reconocimiento y/o de culto social a la existencia de distintas expresiones socio-culturales en el seno del Estado-Nación; y tercero, el fomento a los valores de tolerancia, respeto y solidaridad étnico-cultural, entre las diferentes tradiciones étnico-culturales, político-religiosas y/o económico-sociales que conforman el amplio contexto contemporáneo de la sociedad global -según es posible advertir en el Principio III de las Directrices sobre la Educación Intercultural de la UNESCO: "La educación intercultural enseña a todos los educandos los conocimientos, actitudes y las competencias culturales que les permitan contribuir al respeto, el entendimiento y la solidaridad entre individuos, entre grupos étnicos, sociales, culturales y religiosos y entre naciones" (s/f, p. 39). 
Empero, ninguno de estos tres factores posibilita el logro de la meta fundamental que se propone el multiculturalismo educativo, o la educación intercultural, es decir, la modificación de las actitudes sociales con respecto a la diversidad cultural y la transformación significativa de las propias disposiciones socio-culturales, puesto que:

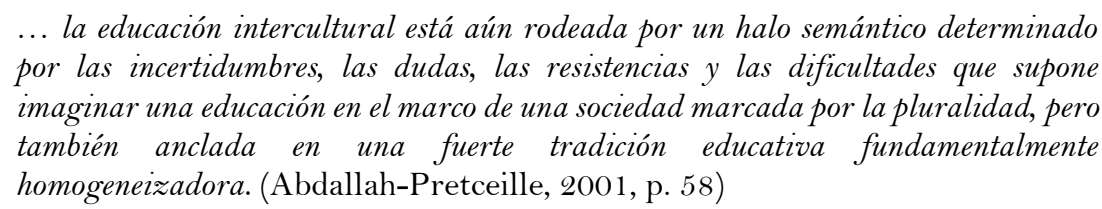

En el primer caso, la afirmación reivindicativa de los pueblos marginados ha desembocado en el modelo de la educación diferenciada y en el emplazamiento de instituciones étnicas -como las Universidades y las Normales Indígenas, verbigracia-, que en los hechos ha tendido a reproducir los mismos fenómenos de exclusión social, discriminación racial, subalternidad política y homogenización cultural que se pretende combatir en la dimensión de las sociedades mayoritarias de los Estados-Nación. En la mayoría de los casos, las instituciones étnicas operan como simples centros educativos para indígenas, que no de fomento a los propios valores culturales identitarios, donde predominan los grupos autóctonos mayoritarios y donde la otredad es segregada; así, por ejemplo, en México, dentro del Subsistema de la Educación Indígena del Estado de Michoacán, los Mazahuas, Nahuas y Otomíes deben subordinarse a los intereses mayoritarios de la Nación Purépecha, que decide sobre las prioridades, políticas y distribución de los intereses institucionales de este sector, donde ocupan la mayoría de los puestos de decisión; mientras que en la Licenciatura en Educación Preescolar y Primaria para el Medio Indígena (Plan 90), de la Universidad Pedagógica Nacional, enMéxico, los únicos que pueden acceder a estudiar son aquellos que dominan alguna lengua indígena y ya se desempeñen como profesores de esta modalidad educativa, es decir, nadie que no pertenezca al propio grupo históricamente marginado puede participar de sus procesos de formación societal. Incluso, en la mayoría de estas instituciones suele reproducirse el mismo modelo tradicional de colonización socio-civilizatoria bilingüe al que pretenden oponerse y trascender, como sucede en la Escuela Normal Indígena y en la Universidad Intercultural Indígena de Michoacán, México.

Por su parte, en el segundo caso, el multilingüismo se presenta en cuanto estrategia de culto cívico a las culturas derrotadas y prácticamente extintas -como sucede en Paraguay donde alrededor del 90\% de la población habla la lengua étnica del Guaraní, pero cuya población indígena apenas si se aproxima al 2\%-; o bien, en tanto dispositivo de interacción social y de facilitación de los procesos de la administración pública del Estado, con la acentuación del problema de la multiculturalidad que provocan los incontenibles flujos migratorios -según acontece en Suecia y en los Países Bajos-; y también, como medio de diálogo, negociación e intercambio socio-cultural que requieren los grupos étnicos y marginados, para insertarse e integrarse en los proyectos de desarrollo nacional - de conformidad con lo que ocurre en México y Guatemala, hacia la última década del siglo XX-. En lo que respecta al último caso, la promoción de los valores que posibiliten el desarrollo de competencias para "aprender a vivir juntos", de acuerdo con el planteamiento de los Cuatro Pilares de la Educación en el Siglo XxI que recupera el informe presentado por Delors (1996) a la UNESCO, pierde de perspectiva que el reconocimiento de la alteridad no se reduce a un asunto moral, o ético, sino que se construye en la dialéctica interacción onto-histórica del yo con el otro y del otro con el yo, es decir, en el proceso de legitimación de la existencia del sí propio en relación con la 
otredad contingente. La legitimidad existenciaria deviene de la relación con el otro, no como mi semejante, según pretende el pensamiento judeo-cristiano, sino como alguien determinado por su propia diferencia, en otras palabras, no se trata de legitimar la existencia de la otredad a partir de la proyección de lo que hay del yo en el otro y que lo convierte en semejante, sino de admitir como pertinente aquello que lo hace precisamente diferente. "Es una relación con el otro concebido individual y colectivamente como diverso y no como extraño o enemigo", según indica Rafael Sáez (2006). Más que un problema moral, o ético, es un dilema de definición onto-histórica.

La tradición occidental se asienta sobre el principio filosófico de la identidad que comporta la necesaria y sistemática depuración de la diferencia, tanto del pensamiento formal como de las prácticas socio-culturales. La alteridad problematiza las certezas que fundamentan la legitimidad del ser y la validez del predominio del proyecto de civilización moderno. La presencia del otro interpela porque cuestiona la pertinencia onto-histórica de la propia existencia. Los fenómenos de discriminación, racismo, xenofobia y segregación, entre otros, provienen de este principio antropocéntrico de la identidad del ser-que tampoco es un fenómeno exclusivo de la cultura occidental, como bien lo evidencian los etnónimos-, los cuales no son nuevos en el desarrollo de la civilización, sino que se proyectan a los albores de las prácticas socio-culturales humanas. La educación formal, en cuanto pliegue institucional de estas mismas prácticas, no puede escapar del carácter homogeneizante que le reconoce Abdallah-Pretceille (2001), porque su función principal es precisamente la transmisión, a las nuevas generaciones, de los valores étnico-culturales, políticoeconómicos y socio-identitarios predominantes en el estrato histórico. La exclusión, discriminación y la misma homogenización son dispositivos sociales de depuración de la diferencia, de la otredad, de la alteridad. En este sentido, el reto fundamental que confrontan los procesos de definición de la educación intercultural es precisamente la trascendencia del pensamiento de la identidad, para situarse en el marco de las relaciones e interacciones de la diversidad. Y la alteridad no sólo se construye en el contexto general de las sociedades multiculturales, sino que acontece, en sus aspectos más finos, dentro del seno de las mismas sociedades monoculturales, como bien se hace patente con las actuales luchas, algunas radicales, de las denominadas "subculturas" y de los movimientos en defensa de la diversidad de género, por reiterar sólo dos ejemplos significativos. La interculturalidad, en cuanto problema onto-histórico, no se define sólo, y en exclusiva, dentro del contexto de las interacciones entre prácticas culturales distintas -no deriva, pues, sólo del fenómeno del multiculturalismo-, sino que deviene de las múltiples formas de significación del ser y de construcción de la identidad propia, aún en el seno mismo de un estrato socio-cultural, o de las denominadas sociedades monoculturales, si se prefiere.

En esta perspectiva, la interculturalidad se trama en el intersticio entre la afirmación de las formas de significación identitaria del ser y el reconocimiento de las diferencias que hacen del otro un alter ego, es decir, no se determina en ninguno de los polos de las relaciones de alteridad, sea por concesión política, reivindicación cultural o maduración moral, o formación ética, de las sociedades mayoritarias con tradición histórica discriminante, ni tampoco por empoderamiento etnogenético, reapropiación lingüísticodiscursiva o autonomía institucional de los pueblos minoritarios tradicionalmente discriminados -sin que ello signifique una oposición, abierta o soterrada, a la legitimidad histórica de cualesquiera de estos procesos contemporáneos-, sino que la acción estratégica intercultural es construida en el encuentro de dos, o más, seres culturales que constituyen expresiones onto-históricas diversas, es conformada en la interacción social 
de dos, o más, entes humanos que representan formas de significación distintas, es determinada en la correlación civilizatoria de dos, o más, identidades ontológicas que configuran modos de ser diferentes. La interculturalidad, pues, es un fenómeno de relación entre individuos, sociedades y proyectos de civilización que disponen de formaciones ontohistóricas diversificadas. Y de hecho, aún las tradicionales estrategias de segregación, discriminación y/o subordinación étnico-cultural son formas de relación intercultural. En consecuencia, una primera aproximación a la definición de la >>educación intercultural $<<$ es la siguiente: proceso de desarrollo de competencias para establecer encuentros, interacciones y correlaciones onto-históricas con la alteridad socio-cultural, a partir de las formas particulares de significación identitaria y el reconocimiento de la legitimidad existenciaria de los diversos modos de devenir el ser en el mundo. En pocas palabras, el núcleo fundamental de la interculturalidad lo constituye las interrelaciones de diferencia.

\section{El fenómeno de la educación en la construcción identitaria}

El respeto irrestricto al derecho inalienable de los individuos, comunidades y pueblos de apropiarse de los valores fundamentales que definen su construcción identitaria y, por ende, su propio devenir civilizatorio, además de la emergente necesidad de diseñar e implementar estrategias formativas para el desarrollo de competencias básica que les posibilite intervenir, de manera significativa, en el desarrollo, potenciación y/o transformación de los contextos socio-culturales y político-económicos en que interactúan, así como la misma concreción societal del proyecto histórico de la Educación Intercultural, inexorablemente comportan un profundo cuestionamiento a los principios nodales del pensamiento enciclopédico-ilustrado que originan y fundamentan la materialización de la Educación Moderna. Al pensamiento de la identidad que constituye el sustrato de la conquista del reconocimiento de la igualdad onto-histórica debe oponérsele la comprensión de la alteridad onto-cultural; al principio lineal sociocivilizatorio del desarrollo evolutivo y progresivo de la Historia es necesario anteponerle el cuántico devenir de la diversidad socio-histórica; al predominio del Conocimiento Formal (científico-disciplinario y técnico-tecnológico) es indispensable contraponer la multiplicidad de saberes socio-culturales; a los procesos de institucionalización educativa es pertinente enfrentarle la desescolarización de los procesos de formación societal; y a la premisa educativa de constituir la utópica Sociedad del Futuro es imprescindible confrontarle la dinámica de conformar a los ciudadanos del presente. La concreción sociohistórica de la Educación Intercultural requiere de la inevitable deconstrucción de los fundamentos, dispositivos procedimentales y medios de legitimación que ha comportado la instauración de la Educación Moderna. Si el control de los significantes culturales posibilitan el dominio socio-político de un pueblo, según ha mostrado ya Bonfil Batalla (1991), entonces, la deconstrucción sistemática de uno de los dispositivos más eficiente del $>>$ control cultural << que ejerce la Civilización Occidental sobre el mundo, en lo general, $\mathrm{y}$ respecto de las comunidades primigenias del continente latinoamericano, en lo particular, supone una acción estratégica de des-colonización socio-política del pensamiento, un acto de liberación histórico-cultural.

En tal perspectiva, resulta conveniente advertir que este proceso de deconstrucción histórica del fenómeno de la Educación Moderna y la consecuente descolonización del 
pensamiento, punto de fractura del control cultural existente, comporta necesariamente la afirmación de los valores tradicionales de la construcción identitaria comunitaria y, por ende, del reconocimiento sistemático de los procesos culturales en que se resuelve su transmisión social. Al respecto, es importante señalar que hasta el presente, el desarrollo de la experiencia educativa en el ámbito de la denominada Educación Bilingüe, Educación Indígena e, incluso, de la misma Educación Intercultural se ha solventado en la copia y adecuación extra-lógica de los conceptos, principios, dispositivos procedimentales y medios de legitimación institucional que han determinado el devenir de la Educación Moderna, esto es: por un lado, la institucionalización estatal de los procesos educativos, como la instauración del Instituto Nacional Indigenista, el Instituto Nacional de Lenguas Indígenas, las Escuelas Normales Indígenas, las Universidades Interculturales y el Tecnológico Superior Purépecha, en México, verbigracia; por otro lado, la yuxtaposición de las concepciones teorético-científico-disciplinarias a los procesos de construcción de los saberes culturales tradicionales y a los procesos de formación societal que comportan, tales como la "medicina tradicional", la "Etno-Matemática", el "Hamlet Purhépecha", la "Filosofía Indígena” y la "Pedagogía Étnica", por ejemplo; y por último, la discriminación positiva que suele excluir a los principales agentes de dominación y homogenización social de los procesos de diversificación e interculturalidad, a través de acciones compensatorias que pretenden subsanar la exclusión histórica de grupos minoritarios, marginados, vulnerables y/o agredidos, entre las cuales se encuentran: becas, normas, políticas y/o programas especiales, que en el caso particular de la interculturalidad educativa delegan en estos mismos grupos la responsabilidad completa de asumir, impulsar y potenciar las relaciones e interacciones de la diversidad socio-cultural, despojando de tal responsabilidad a los sectores para quienes resulta más necesario la apropiación de tales valores societales. Sin embargo, es fundamental señalar que la afirmación de los valores propios de la construcción identitaria mediante la referencia, por semejanza o yuxtaposición, de los valores socio-culturales predominantes, tan sólo refuerzan el sistema de dominio imperante. Pensar un modelo alternativo de educación comporta, por necesidad, la construcción de nuevos dispositivos teóricos y socio-políticos de formación societal.

En la intención de impulsar una auténtica Educación Intercultural, la pregunta más pertinente resulta ser: ¿cómo se transmiten los valores de la construcción identitaria en el devenir de las prácticas socio-culturales, más allá de los medios institucionales, e institucionalizantes, que determinan a la Educación Moderna? El reto fundamental, entonces, es la desescolarización del pensamiento educativo, la apertura de los límites institucionales a las dinámicas propias de la diversidad cultural, de la coexistencia sociohistórica, en el seno del mundo contemporáneo, porque el dispositivo funcional más eficiente de la evangelización socio-civilizatoria de Occidente ha sido precisamente la institución educativa, la escuela. De hecho, en la Aldea Global ya existen múltiples dispositivos emergentes de formación societal, en todos los ámbitos de las prácticas culturales y de construcción del conocimiento social, que se desarrollan al margen y, a veces en franca contraposición, con las políticas y formas de legitimación escolar. En este sentido, la tarea primera que se ofrece a los verdaderos agentes de la Educación Intercultural, es el reconocimiento de los modos y medios específicos de transmisión social del saber cultural construido por la tradición comunitaria, en el propósito manifiesto de diseñar e instrumentar trayectos emergentes de formación en, desde y para el desarrollo de la vida individual y/o colectiva dentro de su propia singularidad socio-histórica. 
En sentido estricto, educar significa para la tradición moderna, siguiendo a Michel Foucault (2012), el disciplinamiento societal de las nuevas generaciones, a fin de que puedan insertarse funcionalmente en las prácticas político-económicas del proyecto de civilización dominante, así como también la reforma ontológico-moral del ser humano para constituir la utópica sociedad del futuro, según he planteado antes; por eso mismo los procesos formativos se realizan en un ambiente profiláctico y aislado del acontecer sociocultural del contexto histórico de vida. Por su parte, en las culturas extra-occidentales, el equivalente de los procesos educativos comporta la finalidad de transmitir la sabiduría tradicional que posibilita la conservación de la vida en el mundo y se realiza en el seno mismo de las prácticas de integración comunitaria. Así, por ejemplo, en la lengua purhépecha jorhengua significa al propio tiempo sabiduría y enseñanza. Sabiduría que al transmitirse se conserva y en ese acto mismo permite la conservación del continuum vital. Las diferentes funciones que desempeñan los individuos y los distintos colectivos en el seno de la articulación onto-histórica de la comunidad, se saben (jorhenani) y quizás se "enseñan" (jorhendanı) en la concreción misma del vivir y del ser comunitario. Los significantes nodales de la sabiduría cultural, en los contextos extra-occidentales, no se desarraigan de las tradiciones sociales en que se construyen, como sucede con la producción del conocimiento científico-disciplinario y su ulterior transmisión social, a través de las instituciones educativas. Por consecuencia, la formación social que implica la construcción identitaria, sea en el ámbito de los pueblos no occidentales, o ya en el entorno de las comunidades emergentes, deviene de la propia práctica cultural que se transforma en tradición socio-histórica.

Así, pues, la Educación Intercultural no es posible mediante la copia y/o la adecuación extra-lógica de los valores identitarios y de los dispositivos de institucionalización de la civilización occidental, porque, en definitiva, sólo tienden a encubrir la continuidad de la evangelización socio-civilizatoria, del control cultural que ejercen históricamente sobre los diversos pueblos del mundo y que han posibilitado la conformación del actual orden global; más bien, por el contrario, demandan no sólo del reconocimiento público de la pluralidad socio-cultural que conforma el sustrato mismo de los sistemas sociales contemporáneos, deconstruyendo el ideal moderno del Estado Nación monocultural, sino también de la afirmación histórica de los valores propios de la construcción identitaria de cada una de las comunidades existentes en el orbe y, por ende, de los valores de interacción intercultural. Legitimar la existencia comunitaria y la identidad cultural a partir de las semejanzas que puedan descubrirse, evidenciarse, asumirse e implantarse en el desarrollo del acontecer histórico particular, con los valores y dispositivos de afirmación civilizatoria de la cultura dominante, en sentido estricto, no significa confirmar la presencia irrefutable de la alteridad, del derecho a la diferencia y, por tanto, de la necesidad impostergable de la Educación Intercultural, todo lo contrario, representa el auto-engaño de camuflajearse de semejante, de prójimo, del ser auténtico, es decir, proyección ilegitima de la sociedad civilizada, desarrollada, que por ello mismo precisa de la evangelización cultural a fin de que pueda desarrollarse plenamente. Pensar la posibilidad de la Educación Intercultural, entonces, comporta la exigencia insoslayable de construir nuevos conceptos educativos que no disfracen las pretensiones evangelizadoras de la cultura dominante. 


\section{Palabras finales}

El reconocimiento de la diversidad social y el multiculturalismo demanda la transformación emergente de los procesos educativos contemporáneos, hacia la apropiación de los valores de construcción identitaria del contexto en que se desarrollan los individuos, a fin de que puedan construir su proyecto personal de vida, además de participar significativamente en la transformación socio-cultural y político-económica de su comunidad de vida, sin soslayar la interacción en el orden de la sociedad global. En cuanto las sociedades contemporáneas se constituyen en el reconocimiento de la alteridad onto-histórica, por tanto, se requiere de una educación que no sólo respete, sino que también potencie la diversidad identitaria, dentro de un marco de diálogo intercultural, donde todos los individuos y comunidades dispongan del derecho de apropiarse de sus propios valores culturales, así como del capital cultural disponible en la actual sociedad del conocimiento.

\section{Referencias}

Abdallah-Pretceille, M. (2001) La educación intercultural. Barcelona: Idea-Books.

Aneas, M. A. (2005). Competencia intercultural, concepto, efectos e implicaciones en el ejercicio de la ciudadanía. Revista Ibero-Americana, 35(5), 25-47.

Birch, J. W. (1974) Mainstreaming: Educable mentally retarder children in regular classes. Minneapolis, MI: University of Minnesota.

Bonfil Batalla, G. (1991) Pensar nuestra cultura. Ciudad de México: Alianza.

Bourdieu, P. y Passeron, J. C. (2005). La reproducción: Elementos para una teoría del sistema de enseñanza. Ciudad de México: Fontamara.

Delors, J. (Comp.). (1996). La educación encierra un tesoro. París: UNESCO.

Dietz, G. (2003). Multiculturalismo, Interculturalidad y Educación: una aproximación antropológica. Granada: EUG.

Dietz, G. y Mateos, L. (2011). Interculturalidad y educación intercultural en México. Un análisis de los discursos nacionales e internacionales en su impacto en los modelos educativos mexicanos. Ciudad de México: SEP.

Foucault, M. (2012). Vigilar y castigar. El nacimiento de la prisión. Ciudad de México: Siglo XXI.

Lyotard, J. F. (2006). La condición postmoderna. Madrid: Cátedra.

Maraña, M. (Coord.). (2010). Derechos culturales. Documentos básicos de naciones unidas. País Vasco: Etxea.

Mclaren, P. (2005). La vida en las escuelas. Una introducción a la pedagogía crítica en los fundamentos de la educación. Buenos Aires: Siglo XXI.

Sartre, J. P. (2008). Los condenados de la tierra de Frantz Fanon. Madrid: FCE.

UNESCO. (2002). Declaración universal sobre la diversidad cultural. Johanesburgo: UNESCO.

UNESCO. (s/f). Directrices de la UNESCO sobre la educación intercultural. París: UNESCO.

Wallerstein, I. (2006) Análisis de sistemas-mundo. Ciudad de México: Siglo XXI. 


\section{Breve CV del autor}

\section{Francisco Guzmán Marín}

Profesor de Educación Primaria, por la Escuela Normal Rural "Vasco de Quiroga". Licenciado en Educación Media en Matemática, por la Universidad Autónoma de Tlaxcala. Maestro en Filosofía de la Cultura, por la Universidad Michoacana de San Nicolás de Hidalgo. Doctor en Ciencias Sociales, Área de Concentración: Cultura Política y Relaciones de Poder, por la Universidad Autónoma Metropolitana, Unidad Xochimilco. Profesor-Investigador de la Universidad Pedagógica Nacional; Coordinador de Sede del Doctorado en Desarrollo Educativo, Énfasis en Formación de Profesores, de la Unidad 161, Morelia, UPN. Premio Nacional de Ensayo "Alfonso Reyes" (1998), por el CNCA y la UANL. Premio Internacional de Poesía en Español "Féile Filíochta”, Irlanda (2003). ORCID ID: 0000-0001-9433-7680. Email: coraxthelastone@yahoo.es 